JOURNAL

of Health Inequalities

\title{
Cholesterol and cardiovascular mortality in Poland. Are we going in the right direction?
}

\author{
Piotr Bandosz \\ Department of Preventive Medicine \& Education, Medical University of Gdańsk, Poland \\ Department of Public Health and Policy, University of Liverpool, United Kingdom
}

ADDRESS FOR CORRESPONDENCE: Piotr Bandosz, Department of Preventive Medicine \& Education, Medical University of Gdańsk, 7 Dębinki St., 80-211 Gdańsk, Poland, e-mail: piotr.bandosz@gumed.edu.pl

Supplementary materials (slides) are available in Webappendix 8 at the journal's website: https://www.termedia.pl/Journal/Journal_of_ Health_Inequalities-100.

Economic and social changes in Poland and other Central European countries in the 1990s created a unique natural experiment in the field of the public health. The introduction of a market economy changed relative prices and availability of different food products, creating a much healthier food environment. Previous ecological and modelling studies showed univocally that the resulting lower atherogenicity of the diet, especially the improved ratio of unsaturated to saturated fats and increased consumption of fruit and vegetables, was the main driver of the sharp mortality fall observed in the 1990s in Poland, Czech, and Slovakia.

However, these favourable changes in quality of consumed fats seem to no longer exist. The mean population cholesterol level is still falling in Poland, but $85 \%$ of this fall between 2002 and 2011 can be explained by statin use, leaving little room for the effect of diet. Furthermore, recent data from the population of Warsaw citizens show an unfavourable trend in the ratio of consumed saturated to unsaturated fats. Fat supply quantity data from the Food and Agriculture Organisation also suggest no further improvement in the types of consumed fats after the year 2000.

The natural experiment in the 1990s showed the enormous potential of structural changes affecting the food environment and increasing longevity in the population. There is also other evidence supporting the power of these kind of interventions. For example, experience from very successful anti-tobacco initiatives showed that regulation and taxation are much more powerful policies than more agentic ones.
Despite this, structural policies aiming to decrease the atherogenicity of the diet are virtually non-existent in Poland. Some of these have already been introduced in several Western European countries. There are, among others, regulations of the amount of salt in food products, processed food reformulation towards healthier nutrients, agricultural subsidies promoting production of healthy foods, a ban of saturated fats, and taxation of sugary drinks.

There are many structural health policies implemented in Poland; for example, anti-tobacco legislation, road traffic regulations, and food sanitation. There are, however, no regulations aiming to decrease the atherogenicity of the diet. We are not even monitoring dietary trends at the national level. While politically challenging, these regulations have the potential to hugely improve the longevity and health of the population.

Key words: cholesterol, cardiovascular, dietary trends, mortality.

\section{DISCLOSURE}

The author reports no conflict of interest. 